\title{
Variação nos ganhos de seleção para caracteres de qualidade de tubérculos de batata na região Sul do Brasil
}

\author{
Genetic gain variation for processing quality traits of potato \\ tubers in the southern region of Brazil
}

\author{
Francisco Saccol Gnocato ${ }^{\mathrm{I}^{*}}$ Dilson Antônio Bisognin ${ }^{\mathrm{I}}$ Paula Kielse $^{\mathrm{I}}$ \\ Mariane Comiran $^{\mathrm{I}}$ Zilmar da Silva Souza ${ }^{\mathrm{II}}$
}

RESUMO

O objetivo deste trabalho foi avaliar o ganho genético para a seleção de caracteres de qualidade de processamento de tubérculos de batata em função dos ambientes de cultivo da região Sul do Brasil. Foram conduzidos experimentos em condições de verão, em São Joaquim/SC, e de primavera e outono, em Júlio de Castilhos/RS, representativos dos principais ambientes de cultivo da batata na região Sul do Brasil. Em cada ambiente, foram avaliados 18 clones de batata para cor de chips e para a composição dos teores de matéria seca, açúcares redutores, amido $e$ amilose. Maior intensidade de seleção pode ser aplicada para os teores de matéria seca e amido, em virtude da menor influência do ambiente na expressão desses caracteres. Para os teores de açúcares redutores e amilose, os ganhos na primavera, verão e outono não são correlacionados $e$, portanto, menor intensidade de seleção deve ser aplicada. $O$ cultivo de verão maximiza os ganhos genéticos e, portanto, a seleção para qualidade de processamento deve ser iniciada nesse ambiente.

Palavras-chave: Solanum tuberosum L., melhoramento de batata, cor de chips, matéria seca.

\section{ABSTRACT}

The aim of this study was to evaluate the genetic gain for processing quality of potato tubers in different growing conditions of the southern region of Brazil. Experiments were carried out during summer of São Joaquim, Santa Catarina State, and spring and autumn conditions of Julio de Castilhos, Rio Grande do Sul State, representative of the growing conditions of the southern region of Brazil. Eighteen clones were evaluated for chip color and content of dry matter, reduced sugars, starch and amylose. Higher gain from selection was achieved for dry matter and starch content, because of the high inheritance of these traits. There was no correlation among summer, autumn and spring growing conditions for reduced sugars and amylose content; therefore low selection intensity should be applied. Summer growing season maximizes the genetic gain; therefore selection for processing quality should be mainly applied in this environmental condition.

Key words: Solanum tuberosum L., potato breeding, chip color, dry matter.

\section{INTRODUÇÃO}

O cultivo da batata (Solanum tuberosum L.) vem ganhando espaço nos países em desenvolvimento que, na última década, liderados por China e Índia, produziram mais da metade do total mundial. Em relação ao consumo, a batata processada aumentou a sua participação no mercado, à medida que a população busca maior praticidade no preparo de seus alimentos (KEIJIBETS, 2008). No Brasil, a batata processada na forma de chips e palitos pré-fritos apresentou o segundo maior crescimento no setor industrial de alimentos no ano de 2010 (SILVEIRA et al., 2011).

Para a cor de chips, sabe-se que elevadas temperaturas durante a fritura favorecem a reação de Maillard, em que os açúcares redutores reagem com os aminoácidos, ocasionando o escurecimento do produto processado, além de conferir sabor amargo (SANNY et al., 2012). Os teores de açúcares redutores variam em função da cultivar, do ambiente de cultivo e da maturidade de colheita,

\footnotetext{
'Universidade Federal de Santa Maria (UFSM), 97105-900, Santa Maria, RS, Brasil. E-mail: fgnocato@gmail.com. *Autor para correspondência.

"Empresa de Pesquisa Agropecuária e Extensão Rural de Santa Catarina (Epagri), Estação Experimental de São Joaquim, São Joaquim, SC, Brasil.
} 
além da condição de armazenamento dos tubérculos (AFFLECK et al., 2012; FREITAS et al., 2012). O teor de matéria seca afeta o rendimento industrial e a textura da batata processada (ROMMENS et al., 2010). O amido, principal carboidrato de reserva dos tubérculos, é formado por polímeros lineares (amilose) e ramificados (amilopectina) de $\alpha$-Dglicose (BLENNOW, 2004). As características de uso e aplicação industrial do amido dependem da relação entre amilose e amilopectina, sendo que, para o processamento na forma de chips, maior teor de amilose beneficia a qualidade sensorial, tornando as fritas mais crocantes (TAGGART, 2004).

A indicação de novas cultivares de batata é efetuada conforme o desempenho em diferentes locais e anos de avaliação, como resultado do somatório dos efeitos de genótipo, de ambiente e da interação genótipo $\mathrm{x}$ ambiente (GA). Os ganhos genéticos, por sua vez, são obtidos em função da magnitude da variância genotípica e dos coeficientes de herdabilidade, enquanto que a avaliação em diferentes locais fornece o valor de estabilidade e adaptabilidade dos genótipos frente às variações ambientais (TAI, 2007). Assim, os ambientes de cultivo podem ser analisados em função da capacidade de expressão fenotípica dos diferentes caracteres, os quais podem ser utilizados para a escolha daqueles que possibilitem maiores ganhos genéticos de seleção (AFFLECK et al., 2012).

O desenvolvimento de tubérculos varia entre os clones para os cultivos de primavera e de outono, atribuindo-se ao outono a época menos favorável ao cultivo. O cultivo de verão de altitude, por outro lado, apresenta condições mais adequadas para a expressão dos caracteres de qualidade de tubérculo (SOUZA et al., 2011). É conhecido que tubérculos produzidos no outono apresentam maturidade irregular, ocasionando rápido acúmulo de açúcares redutores no armazenamento, o que os torna impróprios para o processamento industrial (FREITAS et al., 2012). Além disso, tubérculos imaturos apresentam menor teor de amido e maior variação nos teores de amilose (NODA et al., 2004; MULLER et al., 2009;).

O objetivo deste trabalho foi avaliar o ganho genético para a seleção de caracteres de qualidade de processamento de tubérculos de batata em função dos ambientes de cultivo da região sul do Brasil.

\section{MATERIAL E MÉTODOS}

Os experimentos foram conduzidos na estação experimental da Fundação Estadual de Pesquisa Agropecuária (FEPAGRO), em Júlio de Castilhos/RS $\left(29^{\circ} 15^{\prime} \mathrm{S}, 53^{\circ} 37^{\prime} \mathrm{O}\right.$ e $440 \mathrm{~m}$ acima do nível do mar) na primavera de 2007 e outono de 2008, e da Empresa de Pesquisa Agropecuária e Extensão Rural de Santa Catarina (EPAGRI), em São Joaquim/SC $\left(28^{\circ} 17^{\prime} \mathrm{S}, 4^{\circ} 55^{\prime} \mathrm{O}\right.$ e $1353 \mathrm{~m}$ acima do nível do mar) no verão 2007/2008. Estes locais (subtropical e temperado de altitude) e épocas (primavera, outono e verão) são representativos das condições de cultivo de batata na região sul do Brasil (HELDWEIN et al., 2009) e são os locais de condução das primeiras gerações de seleção do Programa de Genética e Melhoramento de Batata da Universidade Federal de Santa Maria (UFSM).

Duas cultivares ('Asterix' e 'Atlantic') e 16 clones avançados (SJSM01263-1, SJSM012636, SJSM01212-1, SJSM01275-3, SJSM991598, SJSM00211-3, SJSM04514-2, SJSM04503-6, SJSM04503-9, SJSM03475-31， SJSM03425-26, SJSM02382-28, SJSM02377-33, SJSM023173, SJSM02339-1, SJSM02349-1) dos Programas de Melhoramento da UFSM e da EPAGRI foram avaliados para qualidade de processamento dos tubérculos em relação à cor de chips e aos teores de matéria seca, açúcares redutores, amido e amilose. Os experimentos foram conduzidos em um fatorial $18 \times 3$ (clones/ cultivares e ambientes de cultivo), no delineamento em blocos casualizados, com duas repetições. A unidade experimental foi constituída de dez plantas (covas), em fileira única, espaçadas $0,75 \mathrm{~m}$ entre fileiras e $0,30 \mathrm{~m}$ na fileira. Para o plantio, foram utilizados tubérculos semente em estágio de plena brotação, conforme descrito por SOUZA et al. (2011). Os tratos culturais e o manejo seguiram o sistema de produção tecnificado para a cultura da batata (EPAGRI, 2002). A colheita foi realizada após o secamento completo das hastes das plantas, sendo os tubérculos armazenados por 15 dias a $20^{\circ} \mathrm{C}$ para a suberização da periderme, antes de serem avaliados.

Os tubérculos foram avaliados para a cor de chips e para os teores de matéria seca, açúcares redutores, amido e amilose. Para determinar a coloração de chips, foram utilizadas duas fatias transversais e centrais com $2 \mathrm{~mm}$ de espessura, obtidas de cinco tubérculos de cada parcela. A fritura dos chips foi realizada imergindo-se as fatias em gordura vegetal a $180^{\circ} \mathrm{C}$, até cessar as borbulhas. As amostras foram colocadas sobre papel para 
absorver o excesso de gordura e, após, submetidas à leitura visual de cor de chips, atribuindo notas de 2 (mais claro) a 10 (mais escuro) (BISOGNIN \& DOUCHES, 2002). Para quantificar a matéria seca, uma fatia central e transversal de $1 \mathrm{~cm}$ de espessura foi retirada de cada tubérculo da amostra. Após, as fatias foram picadas, acondicionadas em embalagem de papel e colocadas para secar em estufa de ventilação forçada a $60^{\circ} \mathrm{C}$, até massa constante. A quantificação dos teores de açúcares redutores e de amido foi realizada na matéria seca das amostras pelo método do 2,4-dinitrofenol (FREITAS et al., 2006). A fração amilose do amido foi determinada pelo método do complexo iodo-amido (GILBERT \& SPRAGG, 1964).

Os dados foram submetidos à análise de variância individual e conjunta, considerandose genótipo como efeito fixo e ambiente como efeito aleatório. Os estimadores das variâncias genética, ambiental, fenotípica e da interação GA, bem como os coeficientes de herdabilidade e de variação genética foram obtidos pelas esperanças matemáticas dos quadrados médios da análise de variância conjunta. $\mathrm{O}$ estimador da correlação fenotípica (Rf) entre pares de ambientes foi obtido pela equação: $\operatorname{Rf}=\frac{\operatorname{Côv}\left(\mathrm{y}_{1}, \mathrm{y}_{2}\right)}{\sqrt{\hat{\mathrm{V}}\left(\mathrm{y}_{1}\right) \hat{\mathrm{V}}\left(\mathrm{y}_{2}\right)}}, \hat{\mathrm{V}}=$ variância do ambiente. Os ganhos de seleção entre pares de ambientes foram estimados pela equação: $\mathrm{GS}_{\mathrm{jj}}=\mathrm{h}_{\mathrm{j}}{ }^{2} \mathrm{DS}_{\mathrm{j} \mathrm{j}}$, sendo: $\mathrm{GS}_{\mathrm{jj}}$, ganho no ambiente $\mathrm{j}$, com seleção baseada no ambiente $\mathrm{j}$; $\mathrm{h}_{\mathrm{j}}{ }^{2}$ : herdabilidade do ambiente $\mathrm{j} ; \mathrm{DS}_{\mathrm{jj}}$; diferencial de seleção no ambiente $\mathrm{j}$, no qual os indivíduos selecionados são os de melhor desempenho no ambiente j'. Todas as análises foram realizadas com os softwares Microsoft Office Excel 2007 e Genes (CRUZ, 2001).

\section{RESULTADOS E DISCUSSÃO}

No cultivo de primavera, foi verificada diferença significativa $(\mathrm{P} \leq 0,05)$ entre clones de batata para os teores de matéria seca, amido e amilose; no cultivo de verão, para a cor de chips e para os teores de matéria seca, amido e amilose; e, no outono, somente para os teores de matéria seca e amido (Tabela 1). Os parâmetros genéticos e fenotípicos variaram entre os ambientes. O teor de açúcares redutores foi o caráter mais influenciado pelas variações do ambiente, apresentando maiores amplitudes de médias e de coeficientes de variação entre as épocas de cultivo.
Uma vez verificada homogeneidade das variâncias residuais entre os ambientes, realizouse a análise de variância conjunta (Tabela 2), que acusou efeito significativo $(\mathrm{P} \leq 0,05)$ da interação GA para os teores de matéria seca, amido e amilose dos tubérculos. A contribuição da interação GA para o teor de amilose superou em dez vezes a variância genética, indicando que, para esse caráter, o ganho de seleção pode diferir entre os ambientes. Para a cor de chips e teor de açúcares redutores, não houve interação GA, apesar do efeito significativo de ambientes de cultivo.

O cultivo de verão realizado em condições temperadas (altitude) foi o mais favorável à produção de tubérculos para o processamento industrial e apresentou maior número de correlações ambientais significativas (Tabela 3). As condições climáticas do cultivo de altitude favorecem a maturação das plantas e o incremento de qualidade dos tubérculos (SOUZA et al., 2011), como o aumento dos teores de matéria seca, amido e amilose e redução no teor de açúcares redutores e na cor de chips. Segundo AFFLECK et al. (2008), cultivos realizados em ambiente favorável apresentam maior expressão da variância genética, aumentando a eficiência de seleção. Nesse caso, as informações acerca dos parâmetros genéticos e ambientais podem auxiliar no direcionamento dos recursos para os locais de maior importância para o programa de melhoramento, ou seja, que maximizam o ganho genético de seleção, sendo, neste caso, nas condições de cultivo de verão.

Os ambientes menos similares para a seleção de clones foram a primavera e o outono, para os quais não foi observada correlação fenotípica significativa (Tabela 3). Os baixos índices de correlação sugerem que um clone superior no cultivo de primavera não terá o mesmo desempenho no cultivo de outono e vice-versa, fato que tem dificultado a obtenção de cultivares com adaptação para dois cultivos anuais (MÜLLER et al., 2009). Esse resultado deve estar associado às condições contrastantes entre os cultivos de primavera e outono com relação a radiação solar, à temperatura do ar e ao fotoperíodo (HELDWEIN et al., 2009). As condições contrastantes e a falta de correlação fenotípica justificam a necessidade de avaliação dos clones de batata nas condições de outono e primavera, quando o objetivo é desenvolver cultivares adaptadas para dois cultivos anuais.

Para cor de chips, apenas o cultivo de verão apresentou ganhos genéticos expressivos com a seleção e resposta correlacionada ao outono e ao 
Tabela 1 - Valores dos quadrados médios da análise de variância e dos parâmetros genéticos para cor de chips (CC) e teores de matéria seca (MS), açúcares redutores (AR), amido (AM) e amilose dos tubérculos de 18 clones de batata avaliados em três ambientes.

\begin{tabular}{|c|c|c|c|c|c|c|}
\hline Fontes de variação & GL & $\mathrm{CC}$ & MS (\%) & $\mathrm{AR}\left(\mathrm{mg} g\right.$ de $\left.\mathrm{MS}^{-1}\right)$ & Amido (\% na MS) & Amilose ( $\%$ do AM) \\
\hline & & & & ----Primavera----- & -------------------------. & --------------------------. \\
\hline Genótipo & 17 & $0,42^{\mathrm{ns}}$ & $5,19 *$ & $89,86^{\mathrm{ns}}$ & $45,60^{*}$ & $7,43^{*}$ \\
\hline Blocos & 1 & 1,78 & 0,28 & 4,57 & 0,18 & 2,22 \\
\hline Erro & 17 & 0,42 & 0,61 & 71,93 & 6,97 & 1,90 \\
\hline Média & & 4,78 & 20,34 & 11,38 & 82,97 & 24,41 \\
\hline CV\% & & 13,64 & 3,83 & 74,53 & 3,18 & 5,65 \\
\hline $\mathrm{Vg}$ & & 0,00 & 2,29 & 8,97 & 19,31 & 2,77 \\
\hline $\mathrm{Vr}$ & & 0,21 & 0,30 & 35,96 & 3,48 & 0,95 \\
\hline$h^{2}$ & & 0,00 & 0,88 & 0,20 & 0,85 & 0,74 \\
\hline $\mathrm{CVg}$ & & 0,00 & 7,44 & 26,32 & 5,30 & 6,81 \\
\hline Genótipo & 17 & $0,88^{*}$ & $1,98^{*}$ & $\begin{array}{l}38,02^{\text {ns }} \\
---V \text { erão------- }\end{array}$ & $38,61^{*}$ & $25,97 *$ \\
\hline Blocos & 1 & 1,00 & 0,05 & 56,40 & 0,35 & 63,28 \\
\hline Erro & 17 & 0,12 & 0,24 & 31,95 & 7,90 & 9,42 \\
\hline Média & & 4,06 & 23,53 & 13,92 & 83,48 & 23,20 \\
\hline $\mathrm{CV} \%$ & & 8,46 & 2,09 & 40,61 & 3,37 & 13,23 \\
\hline $\mathrm{Vg}$ & & 0,38 & 0,87 & 3,04 & 15,36 & 8,28 \\
\hline $\mathrm{Vr}$ & & 0,06 & 0,12 & 15,97 & 3,95 & 4,71 \\
\hline$h^{2}$ & & 0,87 & 0,88 & 0,16 & 0,80 & 0,64 \\
\hline $\mathrm{CVg}$ & & 15,18 & 3,96 & 12,52 & 4,69 & 12,40 \\
\hline Genótipo & 17 & $1,07^{\mathrm{ns}}$ & $2,75^{*}$ & $\begin{array}{l}175,76^{\mathrm{ns}} \\
\end{array}$ & $39,71^{*}$ & $13,86^{\mathrm{ns}}$ \\
\hline Blocos & 1 & 0,03 & 1,91 & 12,15 & 13,88 & 4,89 \\
\hline Erro & 17 & 0,97 & 0,63 & 108,89 & 15,76 & 6,64 \\
\hline Média & & 6,42 & 21,49 & 30,88 & 79,81 & 25,61 \\
\hline $\mathrm{CV} \%$ & & 15,34 & 3,70 & 33,79 & 4,97 & 10,06 \\
\hline $\mathrm{Vg}$ & & 0,05 & 1,06 & 33,44 & 11,98 & 3,61 \\
\hline $\mathrm{Vr}$ & & 0,48 & 0,32 & 54,44 & 7,88 & 3,32 \\
\hline$h^{2}$ & & 0,10 & 0,77 & 0,38 & 0,60 & 0,52 \\
\hline $\mathrm{CVg}$ & & 3,56 & 4,79 & 18,72 & 4,34 & 7,42 \\
\hline
\end{tabular}

* Significativo a $5 \%$ de probabilidade e ${ }^{\mathrm{ns}}$ não significativo pelo teste $\mathrm{F}$ a $5 \%$ de probabilidade de erro. GL: grau de liberdade, CV: coeficiente de variação, Vg: variância genética, Vr: variância ambiental, $\mathrm{h}^{2}$ : herdabilidade, CVg: coeficiente genético de variação.

conjunto de ambientes (Tabela 4), o que pode estar relacionado à maior estimativa da herdabilidade no ambiente de altitude. Em pesquisas anteriores, no cultivo de primavera, foram verificados ganhos com a seleção para a cor de chips (MÜLLER et al., 2009). A discrepância desses resultados pode ser justificada pelo fato de os clones avaliados terem sido previamente selecionados para cor de chips no cultivo de verão, conforme metodologia de SOUZA et al. (2011), o que restringiu a variabilidade genética para esse caráter.

Para matéria seca, a maior resposta correlacionada entre ambientes ocorreu no cultivo de verão (Tabela 4), no qual os tubérculos apresentaram maior teor de matéria seca e de amido. Os caracteres matéria seca e amido são correlacionados, uma vez que o amido representa a maior parte da matéria seca do tubérculo (FREITAS et al., 2012). Nesse caso, à medida que as condições de cultivo do verão favorecem o acúmulo de matéria seca, ocorre o aumento do teor de amido. No presente estudo, também foi observado que os teores de matéria seca e amido apresentaram alta herdabilidade, permitindo, dessa forma, ganhos correlacionados entre os ambientes.

Os caracteres que tiveram efeito reduzido de clone, seja pela variação do ambiente para os açúcares redutores, seja pela interação GA para amilose, evidenciaram maior dissimilaridade no cultivo de outono. Esse resultado pode estar associado à maior variação da maturidade dos tubérculos que ocorre nessa época de cultivo (BISOGNIN \& STRECK, 2009). Nesse caso, observa-se a inflação do erro experimental, sobretudo 
Tabela 2 - Valores dos quadrados médios da análise conjunta de variância e dos parâmetros genéticos para cor de chips (CC) e teores de matéria seca (MS), açúcares redutores (AR), amido (AM) e amilose dos tubérculos de 18 clones de batata avaliados em três ambientes.

\begin{tabular}{|c|c|c|c|c|c|c|}
\hline Fontes de variação & Graus de liberdade & $\mathrm{CC}$ & MS (\%) & $\mathrm{AR}\left(\mathrm{mg} \mathrm{g}\right.$ de $\left.\mathrm{MS}^{-1}\right)$ & Amido (\% na MS) & Amilose (\% do AM) \\
\hline Blocos/Ambiente & 3 & 0,94 & 0,75 & 24,37 & 4,80 & 23,46 \\
\hline Genótipo & 17 & $1,00^{\mathrm{ns}}$ & $7,21^{*}$ & $114,54^{\mathrm{ns}}$ & $73,55^{*}$ & $17,44^{\text {ns }}$ \\
\hline Ambiente & 2 & $52,69 *$ & $93,77^{*}$ & $4048,37 *$ & $141,88^{*}$ & $52,30^{\mathrm{ns}}$ \\
\hline Genótipo $\mathrm{x}$ ambiente (GA) & 34 & $0,86^{\mathrm{ns}}$ & $1,35^{*}$ & $94,55^{\text {ns }}$ & $25,19 *$ & $14,91 *$ \\
\hline Erro & 51 & 0,76 & 0,49 & 70,92 & 10,21 & 5,99 \\
\hline Média & & 5,08 & 21,78 & 18,73 & 82,09 & 24,41 \\
\hline Coeficiente de variação (\%) & & 17,10 & 3,23 & 44,97 & 3,89 & 10,02 \\
\hline Variância genética & & 0,02 & 0,98 & 3,33 & 8,06 & 0,42 \\
\hline Variância da interação GA & & 0,05 & 0,40 & 11,16 & 7,07 & 4,22 \\
\hline Variância residual & & 0,76 & 0,49 & 70,92 & 10,21 & 5,99 \\
\hline Variância fenotípica & & 0,17 & 1,19 & 18,87 & 12,12 & 2,82 \\
\hline Herdabilidade & & 0,14 & 0,82 & 0,18 & 0,67 & 0,15 \\
\hline Coeficiente de variação genética & & 3,03 & 4,54 & 9,75 & 3,46 & 2,66 \\
\hline
\end{tabular}

${ }^{\text {ns }}$ não-significativo, $*$ e $* *$ significativo pelo teste $\mathrm{F}$, respectivamente, a $5 \%$ e $1 \%$ de probabilidade de erro.

para açúcares redutores e amilose, cujos teores estão diretamente relacionados ao estágio fisiológico dos tubérculos de batata no momento da colheita (ROSS \& DAVIS, 1992; NODA et al., 2004). Sendo assim, sugere-se apenas a aplicação de seleção negativa, possibilitando a eliminação daquele grupo de clones inferiores.

A seleção realizada no verão contribui para o progresso genético nos demais ambientes, especialmente com relação aos teores de matéria seca e amido. Nesse caso, os ganhos de seleção são semelhantes ao praticado no conjunto de ambientes. No melhoramento para qualidade de processamento, o cultivo de verão deve ser priorizado, de modo a maximizar o aproveitamento dos recursos necessários para a condução e avaliação de ensaios de competição de clones de batata. Cabe ressaltar que a avaliação de clones nas condições de cultivo de primavera e outono é fundamental, justificada pelas condições contrastantes de temperatura, fotoperíodo e radiação solar e pela falta de correlação fenotípica entre os ambientes, quando o objetivo é desenvolver cultivares adaptadas para dois cultivos anuais. Nesse caso, a melhor estratégia de melhoramento genético é a avaliação dos clones em condições temperadas e subtropicais de cultivo.

\section{CONCLUSÃO}

Maior intensidade de seleção pode ser aplicada para os teores de matéria seca e amido. A falta de correlação entre os ambientes de cultivo de primavera, verão e outono sugerem a aplicação de baixa intensidade de seleção para os teores de açúcares redutores e amilose e cor de chips. A seleção para qualidade de processamento dos tubérculos de batata deve ser iniciada no cultivo de verão, para maximizar o ganho genético.

Tabela 3 - Correlações fenotípicas entre pares de ambientes para cor de chips (CC) e teores de matéria seca (MS), açúcares redutores (AR), amido (AM) e amilose dos tubérculos de 18 clones de batata avaliados em três ambientes.

\begin{tabular}{|c|c|c|c|c|c|}
\hline Ambientes de cultivo & $\mathrm{CC}$ & MS (\%) & $\mathrm{AR}\left(\mathrm{mg} g\right.$ de $\left.\mathrm{MS}^{-1}\right)$ & Amido (\% na MS) & Amilose (\% do AM) \\
\hline Primavera $\mathrm{x}$ verão & $-0,25$ & $0,87 *$ & $0,58 *$ & 0,17 & 0,20 \\
\hline Primavera $\mathrm{x}$ outono & $-0,28$ & 0,41 & 0,02 & 0,43 & $-0,11$ \\
\hline Verão $\mathrm{x}$ outono & $0,68 *$ & $0,68 *$ & $-0,20$ & $0,58 *$ & 0,05 \\
\hline
\end{tabular}

\footnotetext{
${ }^{\text {ns }}$ não-significativo, * e ** significativo pelo teste $\mathrm{t}$, respectivamente, a $5 \%$ e $1 \%$ de probabilidade de erro.
} 
Tabela 4 - Ganho de seleção e resposta correlacionada de seleção em três ambientes de cultivo para caracteres de qualidade de tubérculo de batata.

\begin{tabular}{|c|c|c|c|c|c|}
\hline \multirow{2}{*}{ Caracteres } & \multirow{2}{*}{ Ambiente de seleção } & \multirow[b]{2}{*}{ Primavera } & \multirow[b]{2}{*}{ Verão } & \multirow[b]{2}{*}{ Outono } & \multirow[b]{2}{*}{ Conjunto } \\
\hline & & & & & \\
\hline \multirow{4}{*}{ Cor de chips ${ }^{2}$} & Primavera & $0,00(0,00)$ & $-0,02(-0,60)$ & $-0,01(-0,13)$ & $0,02(0,38)$ \\
\hline & Verão & $0,00(0,00)$ & $0,48(11,92)$ & $0,06(0,91)$ & $0,06(1,22)$ \\
\hline & Outono & $0,00(0,00)$ & $0,41(10,13)$ & $0,08(1,17)$ & $0,06(1,15)$ \\
\hline & Conjunto & $0,00(0,00)$ & $0,48(11,92)$ & $0,06(0,91)$ & $0,06(1,22)$ \\
\hline \multirow{4}{*}{$\begin{array}{l}\text { Matéria seca } \\
(\% \text { da matéria fresca) }\end{array}$} & Primavera & $1,62(7,94)$ & $0,74(3,15)$ & $0,33(1,54)$ & $0,85(3,90)$ \\
\hline & Verão & $1,29(6,36)$ & $0,89(3,78)$ & $0,55(2,54)$ & $0,87(4,00)$ \\
\hline & Outono & $0,56(2,75)$ & $0,73(3,09)$ & $0,97(4,53)$ & $0,74(3,42)$ \\
\hline & Conjunto & $1,38(6,79)$ & $0,88(3,75)$ & $0,61(2,85)$ & $0,92(7,22)$ \\
\hline \multirow{4}{*}{$\begin{array}{l}\text { Açúcares redutores } \\
\left(\mathrm{mg} \mathrm{g}^{-1} \text { de matéria seca }\right)^{2}\end{array}$} & Primavera & $0,18(0,90)$ & $0,13(0,54)$ & $0,13(0,58)$ & $0,18(0,82)$ \\
\hline & Verão & $0,18(0,86)$ & $0,15(0,63)$ & $0,28(1,28)$ & $0,21(0,98)$ \\
\hline & Outono & $0,12(0,58)$ & $0,12(0,50)$ & $0,43(2,02)$ & $0,20(0,91)$ \\
\hline & Conjunto & $0,15(0,72)$ & $0,14(0,60)$ & $0,37(1,74)$ & $0,21(0,98)$ \\
\hline \multirow{4}{*}{ Amido (\% matéria seca) } & Primavera & $3,37(4,06)$ & $1,82(2,18)$ & $1,40(1,75)$ & $1,92(2,33)$ \\
\hline & Verão & $1,50(1,81)$ & $3,58(4,29)$ & $2,63(3,29)$ & $2,37(2,89)$ \\
\hline & Outono & $1,05(1,26)$ & $2,55(3,05)$ & $2,94(3,69)$ & $2,08(2,53)$ \\
\hline & Conjunto & $3,01(3,63)$ & $2,98(3,57)$ & $2,23(2,80)$ & $2,45(2,99)$ \\
\hline \multirow{4}{*}{ Amilose ( $\%$ amido) } & Primavera & $1,69(6,93)$ & $0,41(1,77)$ & $-0,66(-2,56)$ & $0,08(0,34)$ \\
\hline & Verão & $0,48(1,96)$ & $2,66(11,44)$ & $-0,04(-0,16)$ & $0,24(0,98)$ \\
\hline & Outono & $-0,70(-2,88)$ & $0,12(0,50)$ & $1,51(5,88)$ & $0,11(0,44)$ \\
\hline & Conjunto & $0,64(2,61)$ & $2,19(9,43)$ & $0,28(1,08)$ & $0,24(1,00)$ \\
\hline
\end{tabular}

${ }^{1}$ Considerando os seis clones superiores, incluindo as testemunhas; valores entre parênteses referem-se ao ganho percentual.

${ }^{2}$ Valores dos ganhos de seleção foram multiplicados por -1 .

\section{REFERÊNCIAS}

AFFLECK, I. et al. Genotype by environment interaction effect on yield and quality of potatoes. Canadian Journal of Plant Science, v.88, p.1099-1107, 2008. Disponível em: <http://pubs. aic.ca/doi/pdf/10.4141/CJPS07207>. Acesso em: 22 jan. 2013. doi:. 10.4141/CJPS07207.

AFFLECK, I. et al. Stability of eight potato genotypes for sugar content and French fry quality at harvest and after storage. Canadian Journal of Plant Science, v.92, p.87-96, 2012. Disponível em: <http://pubs.aic.ca/doi/pdf/10.4141/cjps2011066>. Acesso em: 22 jan. 2013. doi: 10.4141/CJPS2011-066.

BISOGNIN, D.A; DOUCHES, D.S. Early generation selection for potato tuber quality in progenies of late blight resistant parents. Euphytica, v.127, p.1-9, 2002. Disponível em: <http://link. springer.com.ez47.periodicos.capes.gov.br/content/pdf/10.102 3\%2FA\%3A1019983503697>. Acesso em: 22 jan. 2013. doi: 10.1023/A:1019983503697.

BISOGNIN, D.A.; STRECK, N.A. Desenvolvimento e manejo das plantas para alta produtividade e qualidade da batata. Itapetininga: Associação Brasileira da Batata, 2009. 30p. il. (Publicação Técnica-ABBA).
BLENNOW, A. Starch bioengineering. In: ELIASSON A. (Ed.). Starch in food: Structure, function and applications. Cambridge: Woodhead Publishing, p.97-127, 2004.

CRUZ, C.D. Programa GENES: versão Windows; aplicativo computacional em genética e estatística. Viçosa: UFV, 2001. 648p.

EPAGRI. Sistemas de produção para batata consumo e batata semente em Santa Catarina. 3.ed. Florianópolis, 2002. 123p.

FREITAS, S.T. et al. Qualidade para processamento de clones de batata cultivados durante a primavera e outono no Rio Grande do Sul. Ciência Rural, v.36, n.1, p.80-85, 2006. Disponível em: <http://www.scielo.br.ez47.periodicos.capes.gov.br/scielo. php? script $=$ sci arttext\&pid $=$ S0103-84782006000100012\&lng $=$ pt\&nrm $=$ iso $>$. Acesso em: 22 jan. 2013. doi: 10.1590/S010384782006000100012 .

FREITAS, S.T. et al. Processing quality of potato tubers produced during autumn and spring and stored at different temperatures. Horticultura Brasileira, v.30, n.1, p.91-98, 2012. Disponível em: <http://www.scielo.br.ez47.periodicos. capes.gov.br/scielo.php? script $=$ sci_arttext\&pid $=$ S010205362012000100016\&lng=en\&nrm=iso $>$. Acesso em 22 jan. 2013. doi: 10.1590/S0102-05362012000100016. 
GILBERT, G.A.; SPRAGG, S.P. Iodometric determination of amylose. In: WHISTLER, R.L. (Ed.). Methods in carbohydrate chemistry starch. New York: Academic, 1964. V.4, p.168-169.

HELDWEIN, A.B. et al. Batata. In: MONTEIRO, J.E.B.A (Org.). Agrometeorologia dos cultivos - $\mathrm{O}$ fator meteorológico na produtividade dos principais cultivos anuais e perenes no Brasil. Brasília: Ministério da Agricultura Pecuária e Abastecimento, p.91-108, 2009

KEIJIBETS, M.J.H. Potato processing for the consumer: developments and future challenges. Potato Research, v.51, p.271-281, 2008. Disponível em: <http://link.springer. com.ez47.periodicos.capes.gov.br/content/pdf/10.1007\%2 Fs11540-008-9104-3>. Acesso em: 22 jan. 2013. doi: 10.1007 s11540-008-9104-3.

MÜLLER, D.R. et al. Expressão dos caracteres e seleção de clones de batata nas condições de cultivo de primavera e outono. Ciência Rural, v.39, n.5, p.1327-1334, 2009. Disponível em: $<$ http://www.scielo.br.ez47.periodicos.capes.gov.br/scielo. php?script $=$ sci arttext\&pid $=$ S0103-84782009000500004\&lng $=$ pt\&nrm $=$ iso $>$. Acesso em: 22 jan. 2013. doi: 10.1590/S010384782009005000078

NODA, T. et al. The effect of harvest dates on the starch properties of various cultivars. Food Chemistry, v.86, n.1, p.119-125, 2004 Disponível em: <http://dx.doi.org.ez47.periodicos.capes.gov. br/10.1016/j.foodchem.2003.09.035>. Acesso em: 22 jan. 2013. doi: 10.1016/j.foodchem.2003.09.035.

ROMMENS, C.M. et al. Tastier and healthier alternatives to French Fries. Journal of Food Science, v.75, p.109-115, 2010 Disponível em: <http://onlinelibrary.wiley.com.ez47.periodicos. capes.gov.br/doi/10.1111/j.1750-3841.2010.01588.x/full>. Acesso em: 22 jan. 2013. doi: 10.1111/j.1750-3841.2010.01588.x.
ROSS, H.A.; DAVIES, H.V. Sucrose metabolism in tubers of potato (Solanum tuberosum L.). Plant Physiology, v.98, p.287-293, 1992. Disponível em: <http://www.plantphysiol.org/content/98/1/287.full. pdf + html $>$. Acesso em: 22 jan. 2013. doi: 10.1104/pp.98.1.287.

SANNY, M. et al. Is lowering reducing sugars concentration in French fries an effective measure to reduce acrylamide concentration in food service establishments? FoodChemistry, v.135, p.20122020, 2012. Disponível em: <http://www.sciencedirect.com.ez47. periodicos.capes.gov.br/science/article/pii/S0308814612010254>. Acesso em: 22 jan. 2013. doi: 10.1016/j.foodchem.2012.06.052.

SILVEIRA, J. et al. Hortifruti Brasil, jul. 2011. Disponivel em: $<$ http://www.cepea.esalq.usp.br/hfbrasil/edicoes/103/mat_capa. pdf>. Acesso em: 20 dez. 2011

SOUZA, Z. da S. et al. Seleção de clones de batata para processamento industrial em condições de clima subtropical e temperado. Pesquisa Agropecuária Brasileira, v.46, n.11, p.1503-1512, 2011. Disponível em: <http://www.scielo.br/scielo. php?pid=S0100-204X2011001100012\&script=sci_arttext $>$. Acesso em: 29 jul. 2013. doi: 10.1590/S0100-204X2011001100012.

TAGGART, P. Starch as an ingredient: manufacture and applications. In: ELIASSON, A. (Ed.). Starch in food: structure, function and applications. Cambridge: Woodhead, 2004. p.363-392.

TAI, G.C.C. The canon of potato science: 7. Genotype-byenvironment interaction. Potato Research, v.50, p.231-234, 2007. Disponível em: <http://link.springer.com.ez47.periodicos.capes. gov.br/content/pdf/10.1007\%2Fs11540-008-9036-y>. Acesso em: 22 jan. 2013. doi: 10.1007/s11540-008-9036-y. 